\title{
OnabotulinumtoxinA Nerve Blocks in the Treatment of Occipital Neuralgia
}

\author{
Andrew Ea ${ }^{*}$, Terence Gray ${ }^{2}$ \\ ${ }^{1}$ University of New England College of Osteopathic Medicine, Biddeford, ME, USA \\ ${ }^{2}$ Mercy Hospital, Interventional Pain Center, Portland, ME, USA \\ Email: *aea@une.edu,grayt@emhs.org
}

Received 7 April 2016; accepted 5 July 2016; published 8 July 2016

Copyright (C) 2016 by authors and Scientific Research Publishing Inc.

This work is licensed under the Creative Commons Attribution International License (CC BY). http://creativecommons.org/licenses/by/4.0/

(c) (i) Open Access

\begin{abstract}
Occipital neuralgia is characterized by severe pain, accompanied by tenderness and trigger points, in the distribution of the greater, lesser, and/or third occipital nerves. Occipital neuralgia is typically idiopathic, but also is characterized as a common form of posttraumatic headache. Typical treatments include nerve blocks with local anesthetic, nerve stimulation, pulsed radiofrequency, and cryoablation. OnabotulinumtoxinA (ONA) has recently been utilized in nerve blocks to treat occipital neuralgia, with the potential for a longer duration of pain relief than local anesthetic. Our study retrospectively examined 63 patients treated for occipital neuralgia, including 19 with ONA. 80 - 155 units of ONA were administered bilaterally in the surrounding musculature. A total of 61 patients, including 17 of those subsequently treated with ONA, were treated with local anesthetic, using a 1:1 mixture of $0.25 \%$ bupivacaine and 1\% lidocaine, plus triamcinolone. Patients reported VAS pain scores before and after their procedures, and again during 4-week follow-up visits. Information on opioid use, overall pain relief, and duration of full relief was also recorded upon followup. Patients treated with ONA exhibited significant decreases in average VAS pain scores from $4.1 \pm$ 2.6 pre-procedure to $2.1 \pm 2.4$ post-procedure $\left(p=2 \times 10^{-5}\right)$, and $3.0 \pm 2.54$ weeks later $(p=$ $0.0234)$. Mean overall relief was $75.8 \% \pm 25.0 \%$. Treatment with local anesthetic suggested equally efficacious reduction of VAS scores; however, treatment with ONA showed a significantly higher percentage of overall pain relief leading to follow-up. Opioid use did not exhibit significant change, regardless of treatment type. Our results support the hypothesis that use of Onabotulinumtoxin A in occipital nerve blocks leads to significant decreases in pain, while possibly exhibiting a longer duration of action than that of local anesthetic.
\end{abstract}

\section{Keywords}

Occipital Neuralgia, OnabotulinumtoxinA, Botox, Bupivacaine, Lidocaine

\footnotetext{
${ }^{*}$ Corresponding author.
} 


\section{Introduction}

Occipital neuralgia is characterized by unilateral or bilateral pain in the distribution of the greater, lesser, and/or third occipital nerves. The pain is typically severe and shooting, stabbing, or sharp in quality. Tenderness and trigger points in the distribution of the affected nerves are characteristically present [1]. While usually idiopathic, occipital neuralgia is a common form of posttraumatic headache [2], and is also associated with the elderly population [3], postoperative complications [4], vascular compression [5], and infectious diseases [6]. Anesthetic nerve blocks are used for diagnosis and treatment of occipital neuralgia, but treatments with the potential for longer-term relief, including nerve stimulation [7], pulsed radiofrequency [8], cryoablation [9], C2 ganglion decompression [10], and botulinum toxin have recently been utilized.

OnabotulinumtoxinA (ONA), commonly known by the brand name Botox, has been utilized in nerve blocks to treat a variety of neuropathic pain syndromes, including chronic migraine [11]. Though its effect on pain is understood to be primarily peripheral, via the decreased release of neurotransmitters [12], recent evidence supports an additional central mechanism [13]. Studies that specifically examine the use of ONA in treating occipital neuralgia are scarce. A recent literature review discovers insufficient evidence for ONA injection treatment of occipital neuralgia, due to the existence of only two case series studies and three case reports [14]. Past studies of ONA blocks of the greater and/or lesser occipital nerves show significant decreases in pain scores [15], as well as improvement in some pain types and quality of life measures [16], but have been limited by small sample sizes. No literature to date has examined a recent, more extensive method of ONA nerve block, in which the 3rd occipital, supraorbital, and auriculotemporal nerves may also be injected, as dependent on the distribution pattern of pain.

We hypothesized that ONA used in occipital nerve blocks would have a significantly longer period of effective pain relief than local anesthetic, while secondarily contributing to a decrease in opioid dosage following treatment.

\section{Methods}

63 patients were treated in our pain clinic for occipital neuralgia between September 2013 and June 2015. All patients met International Classification of Headache Disorders (ICHD-III) criteria for occipital neuralgia [1]. Previous treatments included the prescribed use of muscle relaxants, antidepressants, and opioids. Of this treatment group, 61 were initially treated with diagnostic nerve blocks, while the other 2 patients had been previously diagnosed and referred by other physicians in the Mercy Hospital system. Local anesthesia was administered as a $1: 1$ mixture of $0.25 \%$ bupivacaine and $1 \%$ lidocaine, plus triamcinolone. Both the greater and lesser occipital nerves were targeted, either unilaterally or bilaterally. If supported by patient presentation and ability to reproduce symptoms, the 3rd occipital, auriculotemporal, and/or supraorbital nerves were also blocked. Following an appropriate diagnostic response, 37 patients repeated 1 - 2 more rounds of nerve blocks with the same local anesthetic mixture.

19 of those patients with positive diagnostic blocks progressed to ONA nerve blocks (Table 1). ONA was administered bilaterally at 16, 24, or 31 injection sites, with 5 units per level, for a total of 80 - 155 units. Sites of administration included the occipitalis, temporalis, trapezius, and cervical paraspinal muscles. Headaches that radiated into the distribution of the supraorbital nerves were further treated with injections into the corrugator, procerus, and frontalis muscles.

Patients were asked to rate their pain upon arrival the day of the procedure, and again immediately following the final injection, using the Visual Analog Scale (VAS) [17]. During follow-up visits, typically 4 weeks after the procedure, patients were asked for a 3rd VAS score, duration of full pain relief (recorded as a length of time, i.e. 2 days of $100 \%$ relief), and overall pain relief (typically recorded as a percentage, i.e. $80 \%$ overall relief). In addition, updated dosages of patient medication, including opioids, were recorded in each follow-up. All patient data was collected retrospectively from electronic charts.

Data was analyzed for statistical significance using the Real Statistics Resource Pack (release 3.5.3). Mean VAS scores reported pre-procedure were compared to post-procedure and follow-up scores using a 1-tailed paired t-test with alpha $(\alpha)$ level $=0.05$ and a confidence interval of $95 \%$. A p value less than 0.05 was considered significant. Overall pain relief of those patients treated with ONA was compared to previous relief from their treatments with local anesthetic using a 2-tailed paired t-test ( $\alpha=0.05$, CI $=95 \%$ ). Pain relief following ONA treatment was also compared to the mean relief following the most recent local anesthetic treatments of all 
Table 1. Characteristics of 19 patients treated with OnabotulinumtoxinA nerve blocks.

\begin{tabular}{|c|c|c|c|c|c|c|}
\hline Patient & Age & Gender & $\begin{array}{c}\text { Vas } \\
\text { (pre-procedure) }\end{array}$ & $\begin{array}{l}\text { Opioid dosage (oral } \\
\text { morphine equivalents, mg.) }\end{array}$ & $\begin{array}{c}\text { History of } \\
\text { occipital pain (years) }\end{array}$ & $\begin{array}{l}\text { Possible } \\
\text { etiology }\end{array}$ \\
\hline 1 & 50 & $\mathrm{~F}$ & $7,8,0$ & 0 & Unknown & Cervical spondylosis \\
\hline 2 & 79 & $\mathrm{~F}$ & $5,5,6,7$ & 0 & 3.5 & Cervical DDD \\
\hline 3 & 52 & $\mathrm{~F}$ & $5,6,4$ & 30 & Unknown & Unknown \\
\hline 4 & 57 & $\mathrm{~F}$ & $0,0,0$ & 0 & 1.5 & Unknown \\
\hline 5 & 47 & $\mathrm{~F}$ & 3 & 0 & 35 & Unknown \\
\hline 6 & 41 & $\mathrm{~F}$ & 5,4 & 0 & 1.6 & Unknown \\
\hline 7 & 56 & $\mathrm{~F}$ & $4,4,4$ & 0 & 5 & Whiplash injury \\
\hline 8 & 46 & M & 1 & 0 & 2 & Unknown \\
\hline 9 & 55 & M & 4 & 0 & 10 & Head/neck trauma \\
\hline 10 & 42 & M & 0 & 0 & 10 & Whiplash injury \\
\hline 11 & 51 & $\mathrm{~F}$ & 3,3 & 30 & 13 & Unknown \\
\hline 12 & 50 & $\mathrm{~F}$ & 5 & 52.5 & 1.6 & $\mathrm{C} 1$ fracture \\
\hline 13 & 55 & $\mathrm{~F}$ & 6 & 0 & 0.8 & Unknown \\
\hline 14 & 69 & $\mathrm{~F}$ & 7 & 0 & 5.5 & Unknown \\
\hline 15 & 50 & $\mathrm{~F}$ & 7 & 0 & 20 & Unknown \\
\hline 16 & 65 & $\mathrm{~F}$ & 5 & 30 & 1.3 & Whiplash Injury \\
\hline 17 & 68 & M & 3 & 0 & 1 & Head/neck trauma \\
\hline 18 & 66 & $\mathrm{~F}$ & 10 & 5 & 0.3 & Unknown \\
\hline 19 & 53 & $\mathrm{~F}$ & 1 & 15 & 11 & Head/neck trauma \\
\hline
\end{tabular}

a. VAS: Visual analog Scale; F: Female; M: Male; DDD: Degenerative Disc Disease. Note that multiple VAS scores reflect repeated treatments.

patients (regardless of future treatment with ONA) using a 2-tailed 2-sample t-test with unequal variances ( $\alpha=$ 0.05 , CI $=0.95 \%)$. Again, a p value less than 0.05 was considered significant. For each patient reporting a percent pain relief, only the most recent report following each treatment type was used in statistical analysis, to reduce the disparity in number of treatments per patient.

\section{Results}

The mean age of the 19 patients treated with ONA was 55.4 years. They reported histories of occipital neuralgia averaging $7.2 \pm 9.0$ years. Treatment with bupivacaine/lidocaine nerve blocks prior to ONA therapy resulted in a statistically significant decrease in average VAS pain scores from $5.7 \pm 2.4$ immediately pre-procedure to $1.4 \pm$ 2.0 at the conclusion of the procedure $\left(\mathrm{p}=2 \times 10^{-11}\right)$. At the 4-week follow-up appointments, the mean VAS score had increased to $4.1 \pm 2.9$ (Figure 1 ), but still showed significant improvement from before treatment $(\mathrm{p}=$ $5 \times 10^{-6}$ ). Mean overall relief upon follow-up was $58.0 \% \pm 20.1 \%$ (Figure 2 ).

Subsequent treatment with ONA similarly led to significant decreases in VAS scores, both post-procedure and 4 weeks later. Patients exhibited an average change in VAS pain scores from $4.1 \pm 2.6$ pre-procedure to $2.1 \pm$ 2.4 post-procedure $\left(\mathrm{p}=2 \times 10^{-5}\right)$. The follow-up mean VAS score increased to $3.0 \pm 2.5(\mathrm{p}=0.0234)$. Mean overall relief was $75.8 \% \pm 25.0 \%$.

The mean age of all 61 patients receiving bupivacaine/lidocaine nerve blocks, regardless of future treatment with ONA, was 49.7 years, with an average history of occipital neuralgia of $7.7 \pm 10.3$ years. Treatment with bupivacaine/lidocaine resulted in a decrease in mean VAS score from $5.6 \pm 2.2$ pre-procedure to $1.4 \pm 2.3$ post-procedure $\left(\mathrm{p}=6 \times 10^{-28}\right)$. Upon follow-up, VAS scores had increased to an average of $4.5 \pm 2.8(\mathrm{p}=6 \times$ $\left.10^{-7}\right)$. Mean overall relief was $51.0 \% \pm 33.7 \%$. 


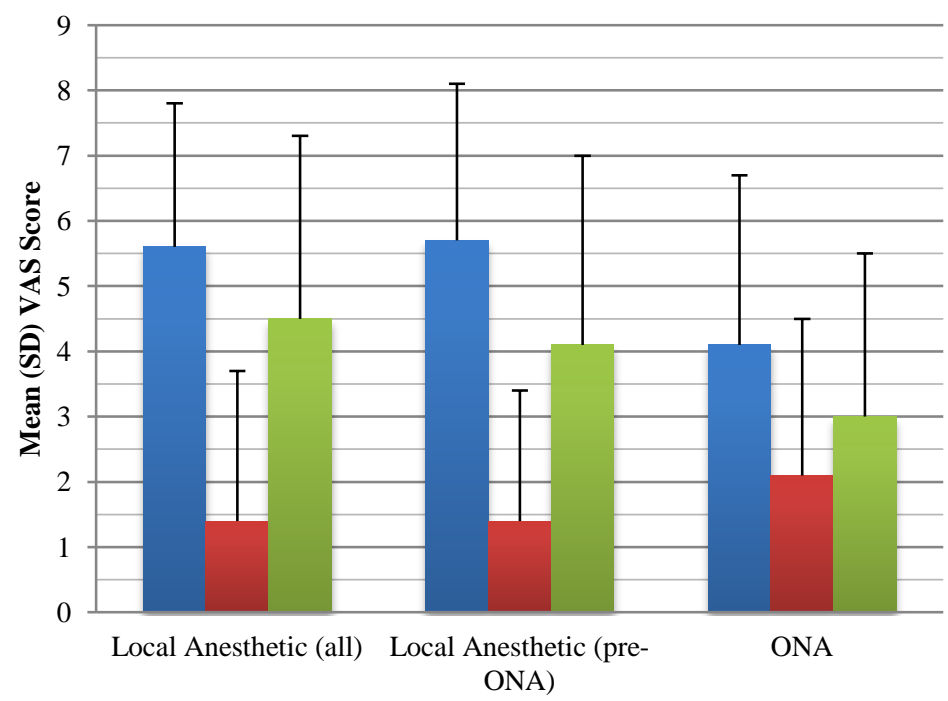

- Pre-Procedure

- Post-Procedure

Follow-Up

Figure 1. Change in average VAS scores following nerve blocks with local anesthetic and ONA, both post-procedure and during 4-week follow-up visits. Procedure types include all local anesthetic nerve blocks (Local Anesthetic (all)), local anesthetic nerve blocks in patients progressing to treatment with ONA (Local Anesthetic (pre-ONA)), and ONA nerve blocks (ONA). Note improvement in average VAS scores in all 3 groups immediately following nerve blocks, with the ONA treatment group exhibiting the lowest average score 4 weeks later. SD: standard deviation. VAS: Visual Analog Scale; ONA: OnabotulinumtoxinA.

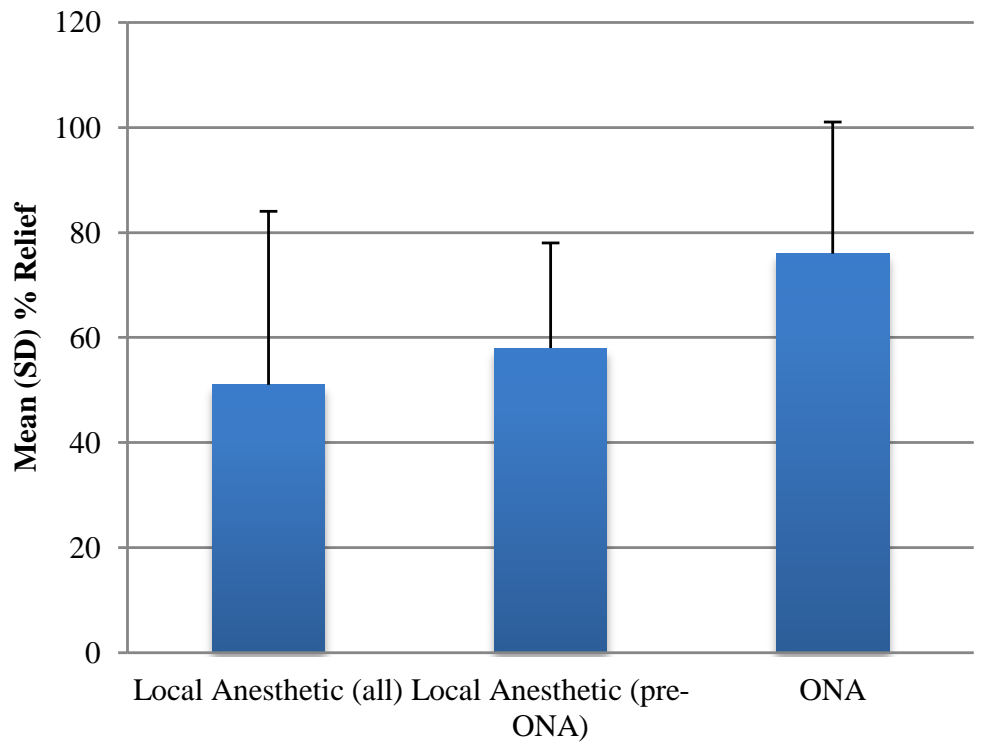

Figure 2. Change in mean percentage pain relief. Note highest percentage of pain relief in ONA group. Treatment group.

Comparison of overall pain relief in the 17 patients treated in our clinic with local anesthetic followed by ONA did not show a significant difference between treatments $(p=0.0543)$. However, when compared to the average pain relief of all patients receiving local anesthetic, treatment with ONA showed a significantly higher percentage of pain relief upon follow-up $(p=0.0126)$. Insufficient data was available to make a comparison of duration of pain relief following each treatment type.

Five of the 19 patients treated with ONA were prescribed opioids prior to treatment. Of these, one slightly increased her dosage from $52.5 \mathrm{mg}$ to $60 \mathrm{mg}$ (morphine equivalents). The other four remained on the same dosages. 20 of the 61 patients treated with local anesthetic, regardless of future treatment with ONA, were prescribed opioids prior to receiving nerve blocks. One patient decreased his dosage upon follow-up (195 mg to $165 \mathrm{mg}$ ), while two others ceased opioid use altogether. The other 17 remained on unchanged dosages. 


\section{Discussion}

We describe the significant improvements in VAS scores following nerve blocks with both local anesthetic and ONA for occipital neuralgia (Table 1, Figure 1), as well as significantly higher average pain relief percentage following treatment with ONA versus treatment with local anesthetic (Figure 2). These findings support the hypothesis that treatment with OnabotulinumtoxinA will lead to more pronounced long-term pain relief than local anesthetic. The secondary hypothesis of decreased opioid dosage following treatment is not supported.

We retrospectively examined three overlapping groups of patients treated in our clinic for occipital neuralgia: patients treated with ONA ( $n=19$, hereafter referred to as the ONA group), patients treated with local anesthetic who progressed to ONA in the future ( $\mathrm{n}=17$, pre-ONA group), and all patients treated with local anesthetic, regardless of future treatment ( $\mathrm{n}=61$, local anesthetic group). All three groups exhibited significant decreases in VAS scores, both immediately following treatment and upon follow-up 4 weeks later. While the ONA group reported the lowest mean VAS scores upon follow-up (3.0 \pm 2.5$)$, supporting a longer effect on pain reduction, this group similarly demonstrated the lowest pre-procedure scores $(4.1 \pm 2.6)$. In fact, comparison of average change of VAS scores after 4 weeks revealed a decrease of $-1.6 \pm 1.9$ in the pre-ONA group, higher that in the ONA $(-1.1 \pm 2.9)$ or local anesthetic $(-1.1 \pm 2.1)$ groups.

Another method we utilized to examine ONA's effect on pain reduction was to compare overall pain relief upon follow-up in the three groups. We hypothesized that this concept of overall pain relief might sum up the extent of a treatment's success better than a single VAS score, which only measured the patient's immediate discomfort. The ONA group reported the greatest mean relief, but was not significantly higher than the pre-ONA group $(\mathrm{p}=0.0543)$. This was likely influenced by a small sample size, with patient records either unclear on the percentage of pain reduction or expressing this reduction in disparate ways. Only 9 patients reporting a percent pain relief following ONA treatment had previously reported a percent pain relief following treatment with local anesthetic, which was necessary for comparison using a paired t-test. In contrast, comparison between percent pain reduction in ONA versus local anesthetic groups using a 2-sample t-test allowed a greater inclusion of patient responses, and showed a significantly greater reduction in the ONA group $(p=0.0126)$. We were unable to collect a significant number of patient responses regarding duration of pain relief. Future studies would benefit from a more standardized form of recording changes in patient pain.

Only four changes in patient opioid dosage were noted in our study, providing little support for our secondary hypothesis of decreased opioid use. That this data did not yield significant results was perhaps unsurprising, given the recent decrease in opioid use due to dependence [18], overdose [19], and opioid-induced hyperalgesia [20]. A 2007 study examining ONA's effect on occipital neuralgia showed opioid use in all six of its patients [15]; in contrast, only 21 of 63 patients in this study had received opioid prescriptions, 19 of which were PRN dosages for short-acting relief.

Our study is the second retrospective study to examine the use of OnabotulinumtoxinA in the treatment of occipital neuralgia, and the first to involve 1) blocks of all three occipital nerves bilaterally and 2) repeated injections. It exhibits a large sample size and updated nerve block techniques. A major limitation lies in the inability to compare the effect of repeated injections of ONA, which has been recently suggested to increase duration of efficacy [21]. There is a wide variance in number of treatments per patient, without a sufficient number of repeated ONA treatments to warrant examination at this point. As with any study involving patient-reported data, subjective measurements are unavoidable, and prone to bias. We conclude that the use of OnabotulinumtoxinA in occipital nerve blocks leads to significant decreases in pain, with greater overall pain relief several weeks after treatment suggesting a longer duration of action than that of local anesthetic. Randomized, placebo-controlled, double-blind trials are indicated to further examine the effect of ONA on occipital neuralgia.

\section{Disclosure}

The authors have no conflicts of interest to report.

\section{References}

[1] Headache Classification Committee of the International Headache Society (IHS) (2013) The International Classification of Headache Disorders. Cephalalgia, 33, 629-808.

[2] Evans, R.W. (2014) Posttraumatic Headaches in Civilians, Soldiers, and Athletes. Neurologic Clinics, 32, $283-303$. 
http://dx.doi.org/10.1016/j.ncl.2013.11.010

[3] Ruiz, M., Pedraza, M.I., de la Cruz, C., Barón, J., Muñoz, I., Rodríguez, C., Celorrio, M., Mulero, P., Herrero, S. and Guerrero, A.L. (2014) Headache in the Elderly: Characteristics in a Series of 262 Patients. Neurologia, 29, 321-326. http://dx.doi.org/10.1016/j.nrl.2013.07.007

[4] Gautschi, O.P., Payer, M., Corniola, M.V., Smoll, N.R., Schaller, K. and Tessitore, E. (2014) Clinically Relevant Complications Related to Posterior Atlanto-Axial Fixation in Atlanto-Axial Instability and Their Management. Clinical Neurology and Neurosurgery, 123, 131-135. http://dx.doi.org/10.1016/j.clineuro.2014.05.020

[5] Shimizu, S., Oka, H., Osawa, S., et al. (2007) Can Proximity of the Occipital Artery to the Greater Occipital Nerve Act as a Cause of Idiopathic Greater Occipital Neuralgia? An Anatomical and Histological Evaluation of the Artery-Nerve Relationship. Plastic and Reconstructive Surgery, 119, 2029-2034. http://dx.doi.org/10.1097/01.prs.0000260588.33902.23

[6] Kihara, T. and Shimohama, S. (2016) Occipital Neuralgia Evoked by Facial Herpes Zoster Infection. Headache, 46, 1590-1591. http://dx.doi.org/10.1111/j.1526-4610.2006.00616_2.x

[7] Sweet, J.A., Mitchell, L.S., Narouze, S., Sharan, A.D., Falowski, S.M., Schwalb, J.M., Machado, A., Rosenow, J.M., Petersen, E.A., Hayek, S.M., Arle, J.E. and Pilitsis, J.G. (2015) Occipital Nerve Stimulation for the Treatment of Patients with Medically Refractory Occipital Neuralgia: Congress of Neurological Surgeons Systematic Review and Evidence-Based Guideline. Neurosurgery, 3, 332-341.

[8] Manolitsis, N. and Elahi, F. (2014) Pulsed Radiofrequency for Occipital Neuralgia. Pain Physician, 17, E709-E717.

[9] Kim, C.H., Hu, W., Gao, J., Dragan, K., Whealton, T. and Julian, C. (2015) Cryoablation for the Treatment of Occipital Neuralgia. Pain Physician, 18, E363-E368.

[10] Choi, K.S., Ko, Y., Kim, Y.S. and Yi, H.J. (2015) Long-Term Outcome and Prognostic Factors after C2 Ganglion Decompression in 68 Consecutive Patients with Intractable Occipital Neuralgia. Acta Neurochirurgica (Wien), 157, 8592. http://dx.doi.org/10.1007/s00701-014-2255-x

[11] Dodick, D.W., Turkel, C.C., De Gryse, R.E., Aurora, S.K., Silberstein, S.D., Lipton, R.B., Diener, H.C. and Brin, M.F., PREEMPT Chronic Migraine Study Group (2010) OnabotulinumtoxinA for Treatment of Chronic Migraine: Pooled Results from the Double-Blind, Randomized, Placebo-Controlled Phases of the PREEMPT Clinical Program. Headache, 50, 921-936. http://dx.doi.org/10.1111/j.1526-4610.2010.01678.x

[12] Francisco, G.E., Tan, H. and Green, M. (2012) Do Botulinum Toxins Have a Role in the Management of Neuropathic pain?: A Focused Review. American Journal of Physical Medicine \& Rehabilitation, 91, 899-909. http://dx.doi.org/10.1097/PHM.0b013e31825a134b

[13] Matak, I., Bach-Rojecky, L., Filipović, B. and Lacković, Z. (2011) Behavioral and Immunohistochemical Evidence for Central Antinociceptive Activity of Botulinum Toxin A. Neuroscience, 186, 201-207. http://dx.doi.org/10.1016/j.neuroscience.2011.04.026

[14] Brown, E.A., Schütz, S.G. and Simpson, D.M. (2014) Botulinum Toxin for Neuropathic Pain and Spasticity: An Overview. Pain Manag, 4,129-151. http://dx.doi.org/10.2217/pmt.13.75

[15] Kapural, L., Stillman, M., Kapural, M., McIntyre, P., Guirgius, M. and Mekhail, N. (2007) Botulinum Toxin Occipital Nerve Block for the Treatment of Severe Occipital Neuralgia: A Case Series. Pain Practice, 7, 337-340. http://dx.doi.org/10.1111/j.1533-2500.2007.00150.x

[16] Taylor, M., Silva, S. and Cottrell, C. (2008) Botulinum Toxin Type-A (BOTOX) in the Treatment of Occipital Neuralgia: A Pilot Study. Headache, 48, 1476-1481. http://dx.doi.org/10.1111/j.1526-4610.2008.01089.x

[17] Carlsson, A.M. (1983) Assessment of Chronic Pain. I. Aspects of the Reliability and Validity of the Visual Analogue scale. Pain, 16, 87-101. http://dx.doi.org/10.1016/0304-3959(83)90088-X

[18] Campbell, G., Nielsen, S., Larance, B., Bruno, R., Mattick, R., Hall, W., Lintzeris, N., Cohen, M., Smith, K. and Degenhardt, L. (2015) Pharmaceutical Opioid Use and Dependence among People Living with Chronic Pain: Associations Observed within the Pain and Opioids in Treatment (POINT) Cohort. Pain Medicine, 9, 1745-1785.

[19] Miller, M., Barber, C.W., Leatherman, S., Fonda, J., Hermos, J.A., Cho, K. and Gagnon, D.R. (2015) Prescription Opioid Duration of Action and the Risk of Unintentional Overdose among Patients Receiving Opioid Therapy. JAMA Internal Medicine, 175, 608-615. http://dx.doi.org/10.1001/jamainternmed.2014.8071

[20] Arout, C.A., Edens, E., Petrakis, I.L. and Sofuoglu, M. (2015) Targeting Opioid-Induced Hyperalgesia in Clinical Treatment: Neurobiological Considerations. CNS Drugs, 6, 465-486.

[21] Lecouflet, M., Leux, C., Fenot, M., Célerier, P. and Maillard, H. (2014) Duration of Efficacy Increases with the Repetition of OnabotulinumtoxinA Injections in Primary Palmar Hyperhidrosis: A Study of 28 Patients. Journal of the American Academy of Dermatology, 70, 1083-1087. http://dx.doi.org/10.1016/j.jaad.2013.12.035 


\section{Submit or recommend next manuscript to SCIRP and we will provide best service for you:}

Accepting pre-submission inquiries through Email, Facebook, Linkedin, Twitter, etc A wide selection of journals (inclusive of 9 subjects, more than 200 journals)

Providing a 24-hour high-quality service

User-friendly online submission system

Fair and swift peer-review system

Efficient typesetting and proofreading procedure

Display of the result of downloads and visits, as well as the number of cited articles

Maximum dissemination of your research work

Submit your manuscript at: http://papersubmission.scirp.org/ 